\title{
Energy Balance of a Glacier Surface: Analysis of Automatic Weather Station Data from the Morteratschgletscher, Switzerland
}

\section{J. Oerlemans and}

\section{E. J. Klok}

Institute for Marine and Atmospheric Research, Utrecht University, Princetonplein 5, $3584 \mathrm{CC}$ Utrecht, The Netherlands.

j.oerlemans@phys.uu.nl

\begin{abstract}
We describe and analyze a complete 1-yr data set from an automatic weather station (AWS) located on the snout of the Morteratschgletscher, Switzerland. The AWS stands freely on the glacier surface and measures pressure, windspeed, wind direction, air temperature and humidity, incoming and reflected solar radiation, incoming and outgoing longwave radiation, snow temperature, and change in surface height (giving melt rates and snow accumulation). The wind is downglacier most of the time. As expected for a flow of katabatic origin, for air temperatures above the melting point we find a correlation between windspeed and temperature. We evaluate all significant components of the surface energy flux. For a (constant) turbulent exchange coefficient of 0.00153 (reference height 3.5 $\mathrm{m}$ ) we obtain a perfect match between calculated and measured ice melt. The sensible heat flux is positive (towards the glacier surface) all the time with the largest values on fine summer days (daily mean values are typically $100 \mathrm{~W} \mathrm{~m}^{-2}$ on the warmest days). The latent heat flux is small and negative in winter. In summer it is mainly positive (condensation), but negative values also occur. Altogether about $75 \%$ of the melt energy is supplied by radiation (shortwave and longwave) and $25 \%$ by the turbulent fluxes.
\end{abstract}

\section{Introduction}

In recent years modeling of glaciers and their response to climate change has shown a strong development (for a general discussion and references see Oerlemans, 2001). A critical component of the models in use is the mass-balance scheme, which relates changes in climate to changes in the specific mass balance. Mass-balance schemes which cover a range of complexity have been designed. At one end of the range is a simple relation between equilibrium-line altitude and annual mean air temperature. At the other end we find spatially distributed energy-balance models that contain a great deal of micrometeorological theory.

Energy/mass-balance models require a description of all the processes that regulate the runoff and the exchange of mass between glacier surface and atmosphere (e.g., the sensible heat flux, the relation between surface conditions and albedo, the effect of clouds on the components of the radiation budget, etc.). Such descriptions cannot be solely obtained from meteorological theory but also require parameterizations based on reliable data sets. This notion has led to the development of automatic weather stations (AWS) suitable for operation on glaciers. However, surface conditions in the melt zones of glaciers are very unstable (high melt rates, forming of crevasses, development of melt water streams, etc.), and consequently it has taken some time to develop stations with a satisfactory performance. Other problems involve energy supply, moisture, and riming. Therefore, one cannot expect that an AWS on a glacier has the accuracy of a regular manned weather station.

The Institute for Marine and Atmospheric Research, Utrecht University, has now been working with year-round AWS on glaciers for more than $5 \mathrm{yr}$. Stations are currently located in the melt zones of the Greenland ice sheet, Vatnajökull (Iceland), Hardangerjökulen and Storbreen (Norway), and the Morteratsch- gletscher (Switzerland). The AWS on the Morteratschgletscher has been working since 1 October 1995. An analysis of the first $3 \mathrm{yr}$ of data can be found in Oerlemans (2000). In 1999 the AWS was upgraded to measure also the humidity and the longwave incoming and outgoing radiation (which were not measured by the old AWS). For the year 2000 a complete data set has been obtained.

Although a large number of energy-balance studies have been performed in the past, most of these studies were restricted to a period of a few weeks or a few months in the summer period (e.g., Ambach, 1963; Björnsson, 1972; Munro and Davies, 1978; Hogg et al., 1982; Munro, 1989; Ohata et al., 1989; Ishikawa et al., 1992; Van den Broeke et al., 1994; Greuell et al., 1997; Oerlemans et al., 1999). The recent deployment of year-round stations in ablation zones makes it possible now to extend the results of such studies. In this paper we make a contribution by analyzing the year-2000 data set from the AWS on the snout of the Morteratschgletscher. This data set is unique in its completeness (very high percentage of data recovery), and quality (all relevant meteorological quantities measured, including the four components of the radiation budget).

After a brief description of the AWS we discuss a selection of data and comment on the typical glacier microclimate as measured by the AWS. Next an analysis of the surface energy flux is given and the melt calculated from the energy balance is compared to the measured ice melt. We determine a drag coefficient for turbulent exchange by matching the calculated melt curve exactly with the observed melt curve.

\section{The AWS on the Morteratschgletscher}

The Morteratschgletscher is a typical valley glacier, located in the Swiss Alps $\left(46^{\circ} 24^{\prime} \mathrm{N}, 9^{\circ} 56^{\prime} \mathrm{E}\right.$; Fig. 1). It is $7.5 \mathrm{~km}$ long, 

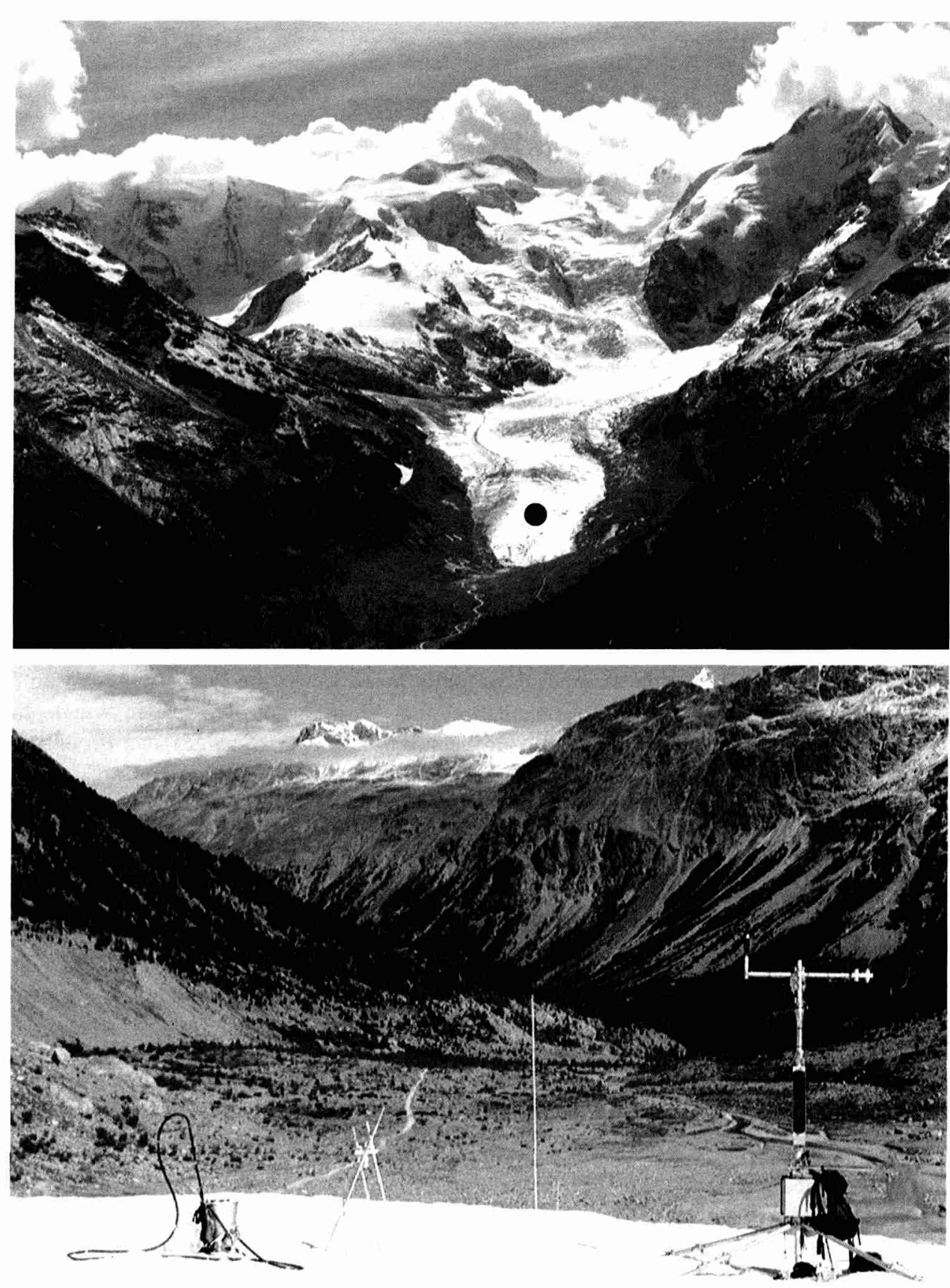

FIGURE 1. The Morteratschgletscher, Switzerland, photographed in September 2001 (upper photograph). The view is towards the south. The glacier snout is at an altitude of 2000 $m$. The highest point is Piz Bernina (on the right in the cloud, $4049 \mathrm{~m})$. The position of the AWS is indicated by a black dot. The lower photograph (looking north) shows the AWS site. On the left is the steamdrill used to place the tripod on which the sonic ranger is mounted (and also used to drill ordinary massbalance stakes). The construction on which the meteorological instruments are mounted has four legs and sinks with the melting ice surface. Note the small solar panel on the mast. has an area of $17 \mathrm{~km}^{2}$ and spans an altitudinal range of about $2000 \mathrm{~m}$. The glacier front is found at an altitude of about 2000 $\mathrm{m}$, which is close to the treeline. The accumulation basin is steep and rugged, whereas the ablation zone has a smaller slope with a few crevassed areas. The equilibrium-line altitude is about $3000 \mathrm{~m}$. The glacier flows in a northerly direction. There is one major tributary coming in from the east (the Perschgletscher). The glacier front has retreated over a distance of about $2 \mathrm{~km}$ since the middle of the 19th century, as witnessed by impressive side moraines.

The AWS is located on the glacier snout (black dot in Fig. 1) at an altitude of about $2100 \mathrm{~m}$. It stands on a relatively flat part of the glacier (slope $\sim 5^{\circ}$ ), about $500 \mathrm{~m}$ from the glacier front. As can be seen in Figure 1, the AWS consists of two constructions. The mast carrying the meteorological instruments stands freely on the ice. It sinks with the melting surface, so the distance of the instruments from the surface remains approximately constant (nominal value $3.5 \mathrm{~m}$ ). However, when snow falls the legs of the mast are buried and the height of the instruments decreases. The second construction (the tripod) is drilled into the ice. A sonic ranger (Campbell SR-50) is mounted on this construction, measuring the distance to the surface. This provides information on ice melt in summer, and on snow accumulation in winter. The setup is completed by three aluminum stakes, placed around the station, at which regular readings of snow depth and ice surface are made (typically five times a year).

The meteorological quantities measured are air temperature and humidity (Vaisala HMP35AC, with forced ventilation), pressure, windspeed and wind direction (Young 05103), and the four components of the radiation budget (longwave in and out, solar in and out; Kipp CNR1). Additionally, battery condition, solar 

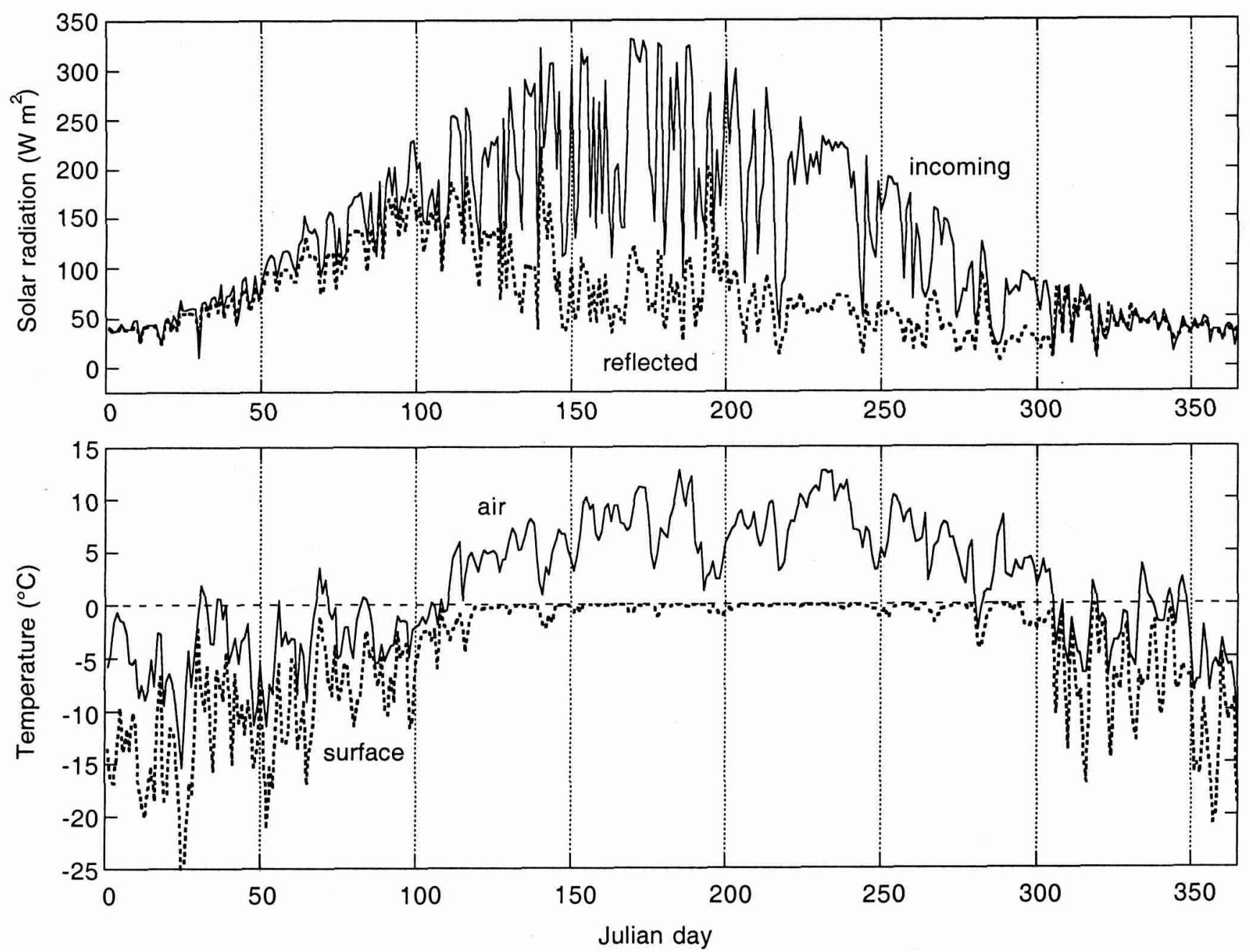

FIGURE 2. Daily mean values of incoming and reflected solar radiation (upper panel) and air and surface temperature (lower panel). The surface temperature has been calculated from the emitted longwave radiation.

panel current, and tilt of the mast are recorded. In winter snow temperatures are measured at four depths. The data are logged on a Campbell CR-10x. Sampling is done every minute and 30minute averages are stored.

The sonic ranger has a reach of about $6 \mathrm{~m}$ over ice, but only about $4 \mathrm{~m}$ over snow (because in this case the reflected signal is more diffuse). Since the melt rates are significant (typically $7 \mathrm{~m}$ in a summer), the tripod and stakes have to be drilled in again at least once a year. The amount of precipitation falling on the glacier snout is rather small. Since the beginning of the investigations (1 October 1995), the snow depth has never exceeded $2 \mathrm{~m}$. Therefore the risk that the instruments are covered by snow is very small.

\section{A Selection of Data}

In Figure 2 daily mean values of incoming and reflected solar radiation are shown, as well as air temperature and surface temperature. Incoming solar radiation ranges from about $40 \mathrm{~W}$ $\mathrm{m}^{-2}$ in midwinter to about $325 \mathrm{~W} \mathrm{~m}^{-2}$ on sunny days in summer. The large variability in summer is related to clouds, of course. It should be noted that the incoming solar radiation is not corrected for the tilt of the instrument and therefore does not represent the global radiation (which is defined with respect to a horizontal surface). However, since the station is normally tilted in such a way that it is more or less parallel to the glacier surface, the incoming solar radiation as measured by the instrument is the relevant quantity for the surface energy balance. From the reflected radiation curve (dashed) it is clear that snow disappears around day 125 .

Although the climate in the Morteratsch valley is rather dry (average relative humidity $64 \%$ ), there are some days on which the radiation measurements are disturbed by snowfall, riming, condensation, or rain, although, during about 25 visits to the station in $5 \mathrm{yr}$, riming was observed only once! Snow cover does occur more frequently, but this is easier to recognize because it shows up in two ways. During significant snowfall the albedo normally exceeds unity because the upward-looking sensor is covered by snow whereas the downward-looking sensor remains clean. At the same time the sonic ranger shows that the distance to the surface decreases. Therefore, snowfall events are easily detected. Fortunately the effect of snowfall on radiation measurements is limited to periods where melt is absent or insignificant. In the cases where the measured reflected solar radiation is larger than the measured incoming solar radiation, we have set the incoming radiation equal to $111 \%$ of the reflected radiation (this corresponds to a fresh snow albedo of 0.9 ). The effect of water drops on the radiation instruments is smaller and occurs only during very short periods of time. We believe that the error 

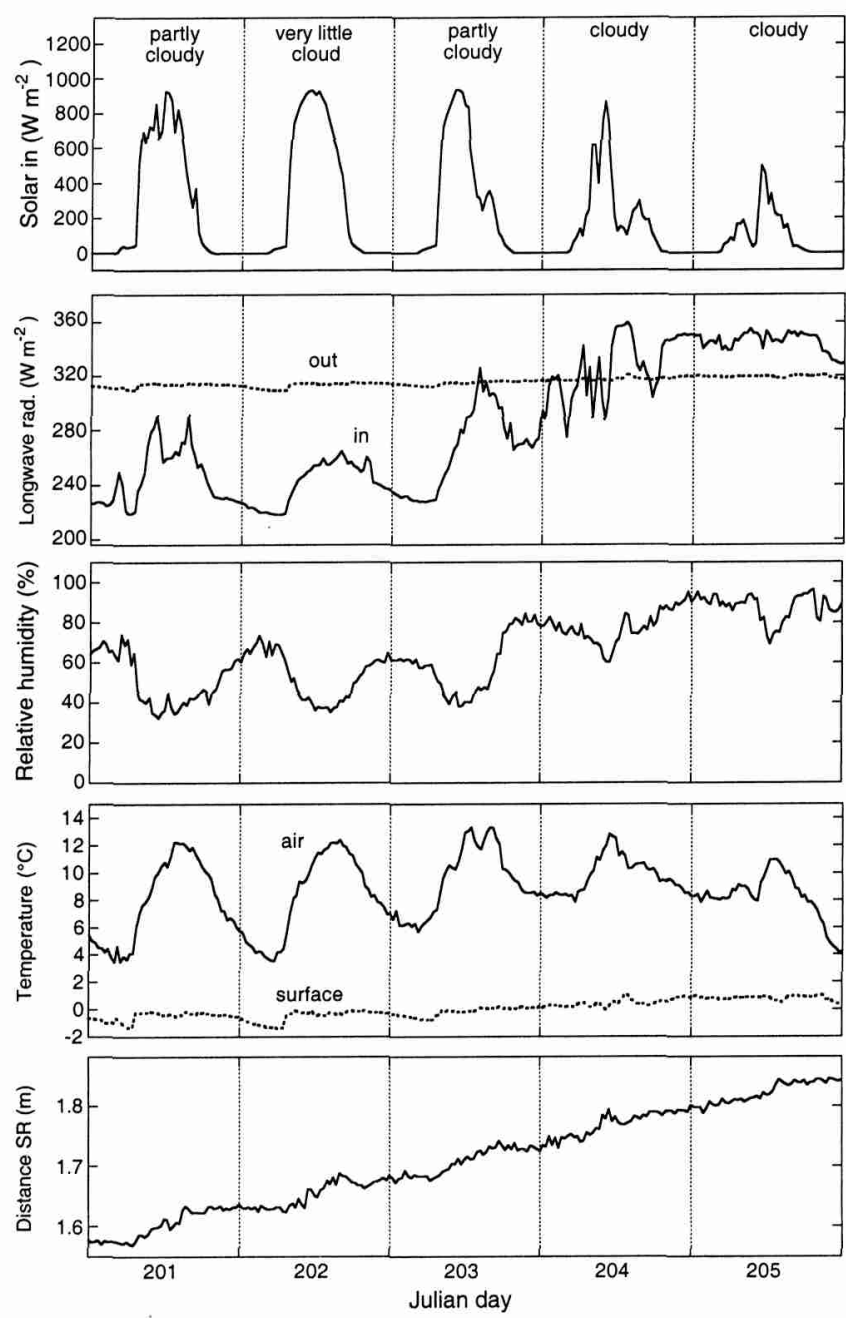

FIGURE 3. Meteorological parameters during a 5-d period in the summer of the year 2000. Note the difference in the various parameters for the first $3 d$ (fine days) and the last $2 d$ (cloudy days).

in the measured annual radiation budget due to ice crystals or water drops on the instruments is less than $1 \%$.

The annual mean incoming solar radiation is $136.1 \mathrm{~W} \mathrm{~m}^{-2}$ and the mean reflected solar radiation is $71.5 \mathrm{~W} \mathrm{~m}^{-2}$, so the annual albedo is about 0.53 . The extraterrestrial irradiance for this site is $292 \mathrm{~W} \mathrm{~m}^{-2}$, implying that altogether only about onequarter of the solar energy available at the top of the atmosphere is actually absorbed by the glacier surface.

Daily mean temperatures are also shown in Figure 2. Both air temperature and surface temperature are shown. The latter was not measured, but calculated from the outgoing longwave radiation $I_{\text {oul }}$ :

$$
T_{s}=\left(I_{\text {our }} / \sigma\right)^{1 / 4}
$$

where $T_{s}$ is the surface temperature and $\sigma$ the Stefan-Boltzmann constant (equal to $5.67 \times 10^{-8} \mathrm{~J} \mathrm{~m}^{-2} \mathrm{~K}^{-4} \mathrm{~s}^{-1}$ ). It has been assumed that the surface emissivity is one. Daily mean values of the air temperature $T_{a}$ range from $-15^{\circ} \mathrm{C}$ to $+13^{\circ} \mathrm{C}$. The surface temperature is always lower than the air temperature (this is so for daily mean values, but not always for 30 -min values). Since $T_{s}$ cannot exceed the melting point, vertical temperature gradients become very large in summer. The annual mean air temperature is $2.1^{\circ} \mathrm{C}$, the annual mean surface temperature $-4.6^{\circ} \mathrm{C}$.

Figure 3 shows more detailed data for a 5 -d period in sum-

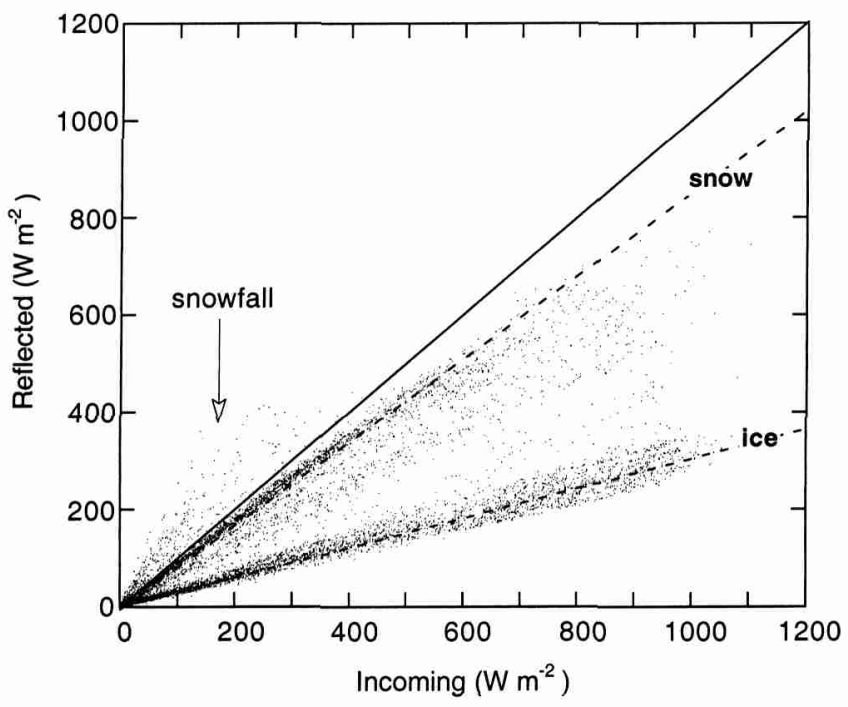

FIGURE 4. A scatter plot of all 30-min values of incoming versus reflected solar radiation. During or shortly after snowfall daily albedos can exceed unity because the upward-looking sensor is covered by snow.

mer. The relation between incoming longwave radiation and cloud conditions (as obvious from the solar radiation curve) shows up clearly. As is normally seen in records like these, the daily cycle in temperature and relative humidity is larger on sunny days. The lowest panel shows the record from the sonic ranger. Apparently, about $25 \mathrm{~cm}$ of ice melts in this 5 -d period. Although the data are noisy, a daily cycle in the melt rate can be seen for the sunny days, but not for the cloudy days.

It is well known that the surface albedo on glaciers varies enormously in space and time. In fact, designing a scheme for the evolution of the surface albedo is one of the largest challenges in glacier mass-balance modeling. Oerlemans and Knap (1998) analyzed an earlier 1-yr record from the Morteratsch AWS and tested some albedo schemes. Here we show a scatter plot of half-hourly values of incoming and reflected solar radiation (Fig. 4). A clustering of the data points into two groups is evident. One group of points represents a snow surface (fresh and old) and the other group of points represents an ice surface. There are also data points for which the reflected radiation is larger than the incoming radiation. As explained above, these points represent situations in which snow is covering the sensor facing upward.

The annual mean windspeed measured by the AWS is only $2.8 \mathrm{~m} \mathrm{~s}^{-1}$. Further analysis of the wind data reveals that katabatic flow dominates (Fig. 5). During about $90 \%$ of the time the wind blows downglacier. Although the nature of the katabatic forcing may be different in summer and winter, on the Morteratschgletscher there is no noticable difference in the frequency of occurrence of downslope flow (Oerlemans, 2001). In summer the forcing of the katabatic flow (in the case of valley glacier also termed glacier wind) is proportional to the temperature deficit, defined as the difference between the air temperature just above the glacier surface and the temperature of the ambient atmosphere at the same altitude not influenced by the presence of the glacier surface.

Next we turn to the measurements of the sonic ranger. The data have a gap (Fig. 6), because the tripod melted out (due to unfortunate timing of the visits to the station), but the stake readings make it possible to combine the records from the old and newly drilled tripod. The snow cover lasts until day 127. 


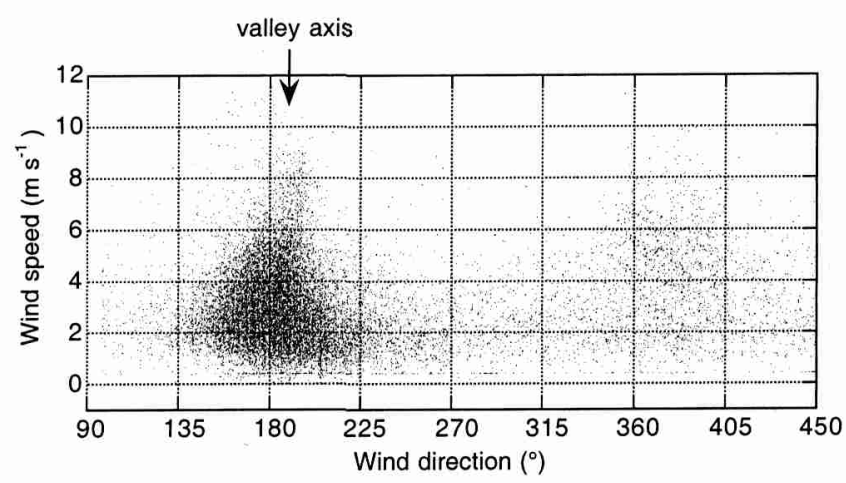

FIGURE 5. A scatter plot of all 30-min values of windspeed versus wind direction. The wind has a strong preference to blow downslope along the valley axis.

Runoff is not measured, but it is likely that runoff starts when the snowpack is heated up to the melting point by refreezing of percolating meltwater. This is the case at day 110 (see Fig. 7). We estimate the total amount of winter snow at $0.236 \mathrm{~m}$ w.e. (meters of water equivalent). This is based on accumulating all fresh snow as measured by the sonic ranger (including measurements from the year 1999) and assuming a density of $180 \mathrm{~kg}$ $\mathrm{m}^{-3}$ for fresh snow. The resulting mass of snow on 5 March then agrees well with the total mass obtained from a snowpit study.

Some other events are listed in Table 1. We mention that $20 \mathrm{~cm}$ of snow fell on 10 July. Apart from the direct addition of mass to the glacier surface, the related increase in surface albedo delays the melting process by a few days. There were two snowfall events in October, but the ice surfaced again. The start of the winter snowpack was on 30 October.

A close-up of the development of the snowpack in winter and its decay in early summer is shown in Figure 7. Snow temperatures measured at approximately 0.25 and $0.5 \mathrm{~m}$ above the ice surface are also plotted. The snow temperature at $0.5 \mathrm{~m}$ shows large fluctuations because until day 90 the sensor is just below the snow surface. The temperature fluctuations at $0.25 \mathrm{~m}$ are of a smaller amplitude and also smoother in time. It is likely that the rapid heating of the snowpack on days 100 and 110 is due to refreezing of meltwater. The decay of the snowpack is very fast.

We conclude that the operation of an AWS on a melting glacier snout is possible and provides valuable insight into the characteristic microclimate of a valley glacier.

\section{The Surface Energy Flux}

The approximate surface energy flux $\psi$ (unit $\mathrm{W} \mathrm{m}^{-2}$ ) can be written as

$$
\psi=S_{\text {in }}+S_{\text {out }}+I_{\text {in }}+I_{\text {out }}+H_{\text {se }}+H_{\text {la }}
$$

where $S_{\text {in }}$ and $S_{\text {out }}$ are incoming and reflected solar radiation, $I_{\text {in }}$ and $I_{\text {out }}$ are incoming and outgoing longwave radiation, and $H_{\text {se }}$ and $H_{l a}$ are the turbulent fluxes of sensible and latent heat. The conductive heat flux from or into the snow/ice is neglected. Detailed studies have shown that this is justified on glaciers with considerable mass turnover (e.g., Greuell and Oerlemans, 1987; Kuhn, 1989). The same applies to the amount of sensible heat brought to the surface by rain or snow.

When the surface is at the melting point, the melt rate $M$ (unit $\mathrm{kg} \mathrm{m}^{-2} \mathrm{~s}^{-1}$ ) is simply

$$
M=\psi / L_{m}
$$

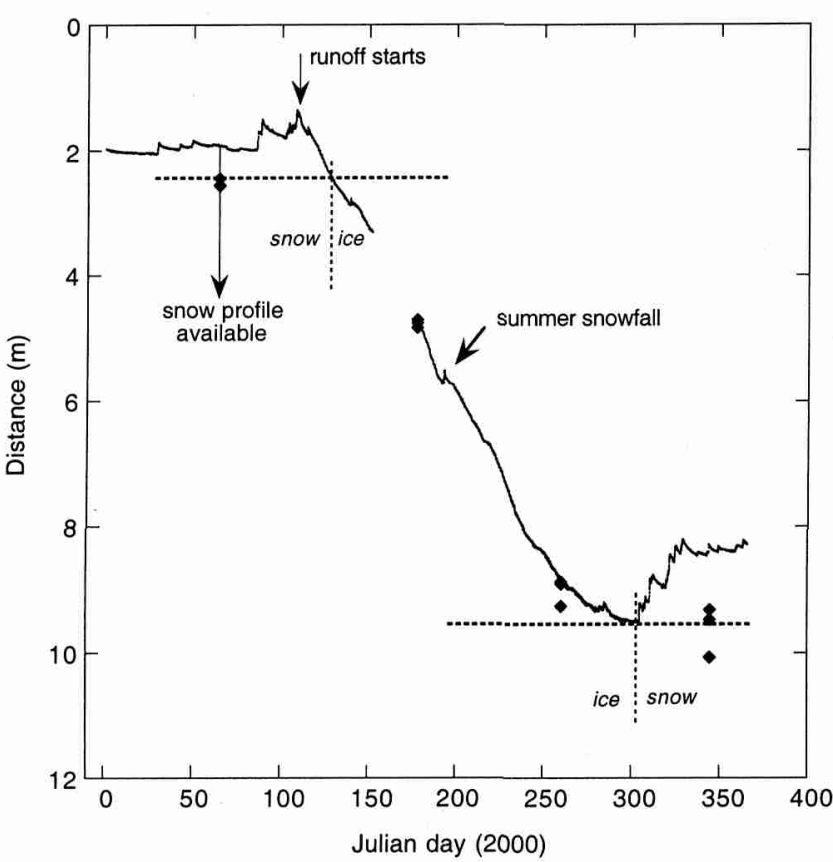

FIGURE 6. The record of the sonic ranger and the type of surface (ice/snow). The horizontal dashed lines show the ice level at the beginning and end of the ablation season. Stake measurements ( 3 stakes) are indicated by diamonds.

where $L_{m}$ is the latent heat of melting. To obtain melt in units of ice or snow depth, $M$ should be divided by the appropriate density.

The radiative components have all been measured directly, but the turbulent fluxes have not. These fluxes should be calculated from the measurements of windspeed, temperature, and humidity. We use the bulk approach (e.g., Garratt, 1992)

$$
\begin{aligned}
& H_{s e}=\rho c_{p} C_{s e} v\left(T_{a}-T_{s}\right) \\
& H_{l a}=0.622 \rho L_{v} C_{s e} v\left(e_{a}-e_{s}\right) / p .
\end{aligned}
$$

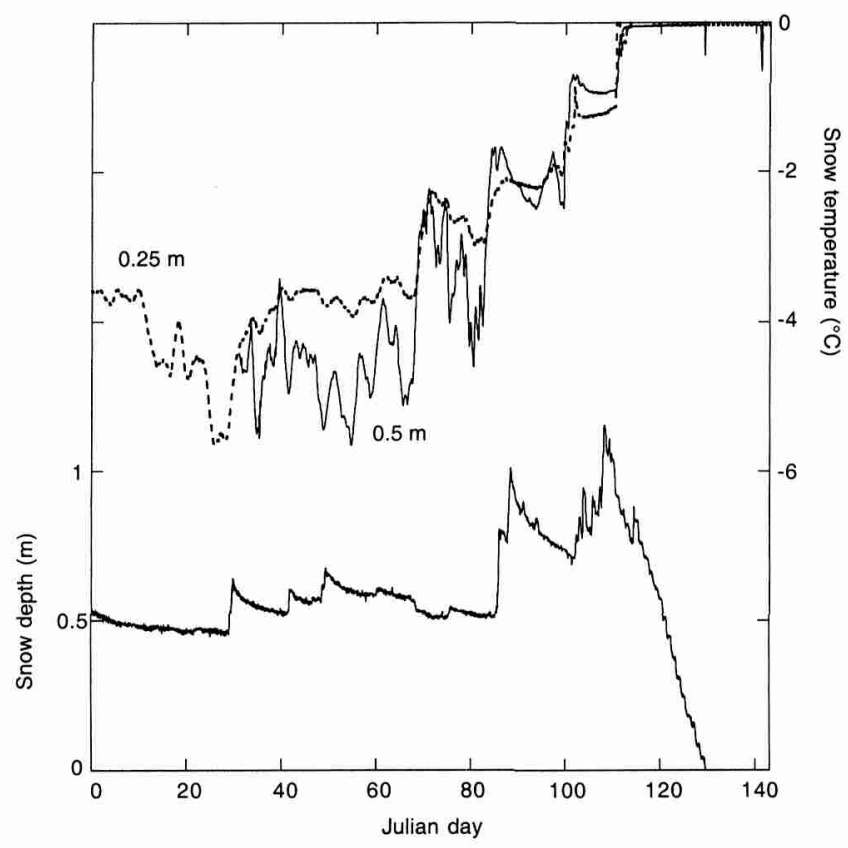

FIGURE 7. Evolution of the snow cover as seen by the sonic ranger (lower curve) and two snow temperature sensors (upper curves). 
TABLE 1

A summary of the surface conditions at the AWS site (year 2000)

\begin{tabular}{ccc}
\hline \hline Day & Date & \multicolumn{1}{c}{ Conditions } \\
\hline $1-65$ & 1 January-6 May & Snow \\
65 & 5 March & Snow profile (density/temperature) \\
110 & 19 April & Snowpack at melting point \\
$110-127$ & 19 April-6 May & Snowpack runs off \\
114 & 23 April & Last winter snow: total mass $0.236 \mathrm{~m}$ w.e. \\
138 & 18 May & $9 \mathrm{~cm}$ of snow \\
192 & 10 July & $20 \mathrm{~cm}$ of snow \\
282 & 8 October & $5 \mathrm{~cm}$ of snow \\
284 & 10 October & $12 \mathrm{~cm}$ of snow \\
304 & 30 October & Winter snowcover starts \\
\hline
\end{tabular}

In these equations $\rho$ is air density, $c_{p}$ is the specific heat of dry air, $C_{s e}$ is the exchange coefficient (assumed to be equal for sensible and latent heat), $v$ is windspeed, $e_{a}$ is vapor pressure, $e_{s}$ is vapor pressure at the surface (assuming saturation), $p$ is the atmospheric pressure, and $L_{v}$ is the latent heat of vaporization. For a melting surface $e_{s}=610.8 \mathrm{~Pa}$. We have not used stability corrections, because in our judgment it has not been shown that this works well in glacier winds with a wind maximum only a few meters above the surface (Munro, 1989; Oerlemans, 1998).

We first consider the period from day 127 until day 304. In this period the surface consists of ice (except for a few days) and the height of the instruments can be considered constant. A perfect match between observed and calculated melt is obtained with $C_{s e}=0.00153$ (note that this is for a reference height of $3.5 \mathrm{~m}$ ). The observed and calculated melt curve are shown in Figure 8. A correction has been made for the summer snowfalls (i.e., some additional mass has to be melted). Compared to the total melt in the period, this correction is small. The calculated melt curve has been anchored to the observed curve at day 127 . It is clear that even the fine-scale fluctuations in the melt rate show up in the energy-balance calculation. Given the fact that

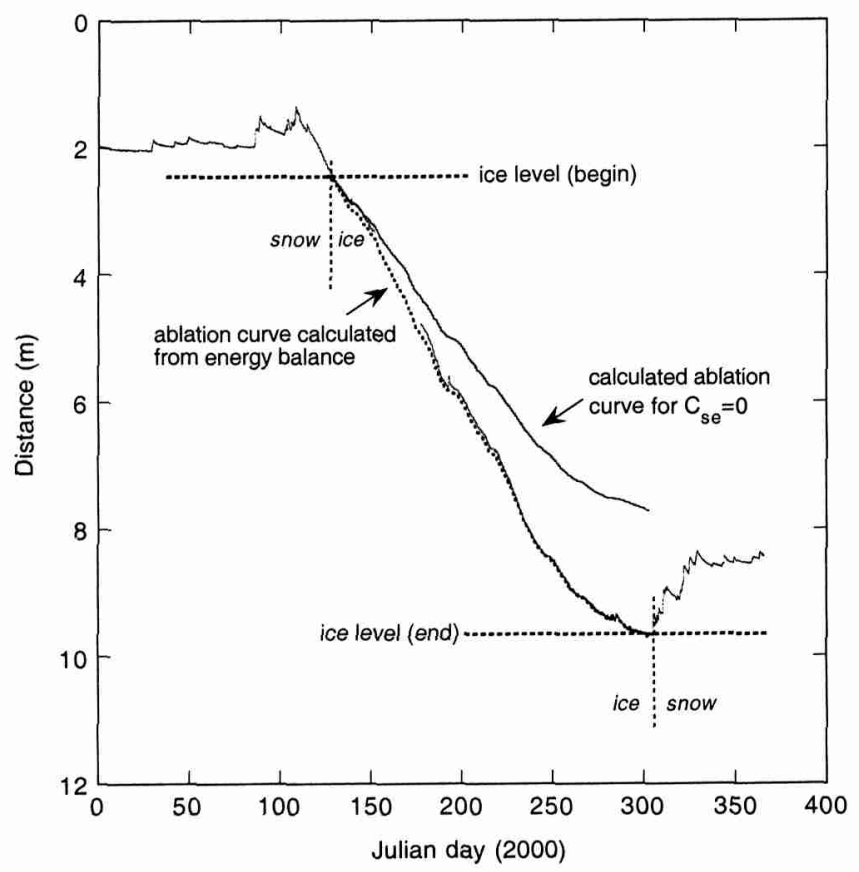

FIGURE 8. A comparison of the observed and calculated ice melt curve for the period with ice at the surface (day 127 until day 303). the data from the sonic ranger is a point measurement on an unevenly melting ice surface, a better result cannot be expected.

Since the rate of snowmelt and runoff was not measured (this would require knowledge of the snow density profile at any moment) it is not possible to check the melt of snow with the energy flux. Nevertheless, it is interesting to determine the turbulent fluxes for the entire year. We calculated the fluxes from equations (4) and (5) by using the same value for $C_{s e}(0.00153)$. Since a drag coefficient or turbulent exchange coefficient is defined with respect to a reference height, it is desirable to correct the measured temperature for differences in instrument height. We now explain how this has been done.

In view of the problems involved in the analysis of wind and temperature profiles in katabatic flows (Kuhn, 1978; Munro, 1989; Oerlemans, 1998), in our further discussion we will assume that the atmosphere is neutrally stable. The bulk exchange coefficient can then be related to $z_{0}$ and $z_{T}$, which are the surface roughness lengths for momentum and heat (e.g., Kondo and Yamazawa, 1986):

$$
C_{s e}=\kappa^{2}\left(\ln \left(z / z_{0}\right)\right)^{-1}\left(\ln \left(z / z_{T}\right)\right)^{-1} .
$$

In this equation $\kappa$ is the Von Kármán constant, and $z$ is the reference height (in this case the instrument height). Strictly speaking, equation (6) is valid only if the turbulent Prandtl-number is close to unity. Equation (6) shows that, if a value for $C_{s e}$ is available and $z_{T}$ is to be determined, a value for $z_{0}$ (or $\eta=$ $z_{T} / z_{0}$ ) is needed. Several studies (e.g., Andreas, 1987; Bintanja and van den Broeke, 1995; Denby, 2001) have shown that $\eta$ is related to the roughness Reynolds number $\left(R e_{*}=u_{*} \mathrm{z}_{0} / v\right.$, where $u_{*}$ is the friction velocity and $v$ the viscosity of the air). However, the roughness Reynolds number cannot be calculated from the present data set because it requires wind speed at at least two heights. Therefore we use the characteristic value $(\eta=0.05)$ found by Smeets et al. (1999) from an extensive analysis of profile measurements carried out in the melt zone of the Pasterze glacier (Austria). These measurements are described in detail in Smeets et al. (1999). Solving equation (7) for $\eta=0.05$ and $C_{\text {se }}$ $=0.00153$ then yields $z_{T}=2.0 \cdot 10^{-5} \mathrm{~m}$.

The next step is to relate a quantity measured at a height $z_{m}$ to the reference height $z_{r}=3.5 \mathrm{~m}$. From the standard logarithmic temperature profile for neutral stratification it is easily verified that

$$
T_{r}^{\prime}=T_{s}+\left(T_{m}-T_{s}\right) \frac{\ln \left(z_{r} / z_{T}\right)}{\ln \left(z_{m} / z_{T}\right)}
$$

where $T_{m}$ is the temperature measured at height $z_{m}$ and $T^{\prime}{ }_{r}$ then is the temperature reduced to the reference height which can be 

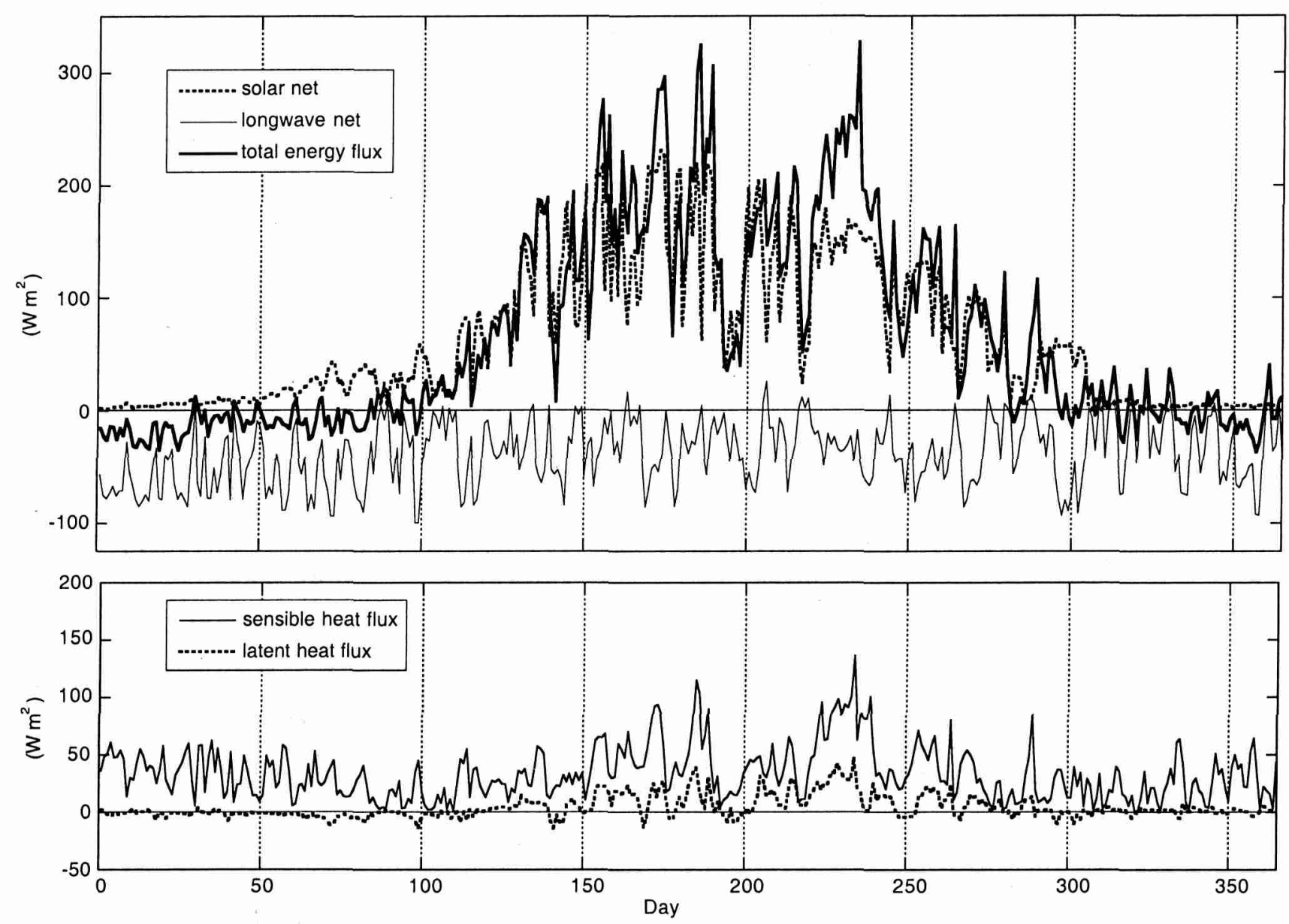

FIGURE 9. Components of the surface energy budget (daily mean values). The heavily drawn line (upper panel) is the total of the net solar and longwave radiation, the sensible heat flux, and the latent heat flux.

used in the calculation of the turbulent flux. Similar corrections have been made to the humidity and wind speed.

We are now able to calculate the components of the surface energy flux for the entire year. The turbulent exchange coefficient is assumed to be constant. This assumption is made because no information is available on how the roughness lengths change in the course of the year. Although snow generally has a smaller roughness length, the variation is large. Old melting snow can have a roughness length as large as that of melting ice, while for a smooth fresh snow cover the roughness length can be two orders of magnitude smaller. Fine-scale structures in a snow surface generated by wind action may also contribute substantially to changes in the roughness length. In view of these complications we kept the drag coefficient constant. This probably implies an overestimation of the turbulent flux in wintertime, but it is impossible to quantify the error. However, the turbulent fluxes in wintertime do not play a role in the melting process.

The resulting diagnosis of the energy budget, in terms of daily mean components, is summarized in Figure 9. The total surface energy flux is dominated by solar radiation. The longwave radiation balance does not exhibit a marked seasonal cycle. Positive daily mean values are very rare, in spite of the fact that in summer the amount of outgoing longwave radiation is limited because the surface temperature cannot exceed the melting point.

The sensible heat flux shows the largest values on warm days in summer. The peak daily mean value is about $135 \mathrm{~W} \mathrm{~m}^{-2}$. Also in the winter months the sensible heat flux is positive and of an appreciable value, because surface temperature is lower than air temperature. As a result, the net surface energy flux in winter is only slightly negative. In winter the largest components of the energy flux are the longwave radiation budget (negative) and the sensible heat flux (positive). We should realize, however, that the sensible heat flux may be overestimated because the turbulent exchange coefficient is probably somewhat smaller in winter (smoother surface due to a thick snowpack).

The latent heat flux is generally smaller than the sensible heat flux. In the winter halfyear small negative values are the rule, although there are also days with deposition (riming). In summer the flux is mostly positive (condensation), but attains negative values on the driest days (low humidity). The annual amount of mass exchange between atmosphere and surface due to the latent heat flux is $18 \mathrm{~mm}$ of water equivalent (towards the glacier surface).

\section{Summary and Discussion}

The present study demonstrates that the operation of automatic weather stations in the melt zones of glaciers delivers useful and interesting data. It has taken some years of experience to find the best sensors, to minimize the power requirements, and to find a good construction that can survive on an unstable surface in a harsh climatic environment. The quality of the data is less than the normal standard for a manned station, but sufficiently good to analyze the exchange of mass and energy between the atmosphere and the glacier surface. 
TABLE 2

A comparison of bulk turbulent exchange coefficients obtained in different studies ${ }^{a}$

\begin{tabular}{|c|c|c|c|}
\hline Study & Location & Duration & $C_{S E}\left(10^{-3}\right)$ \\
\hline Hogg et al. (1982) & South Georgia & {$[u, T$ measured at $1 \mathrm{~m}]$} & 1.7 \\
\hline \multirow[t]{3}{*}{ Hay and Fitzharris (1988) } & Ivory Glacier, & $55 \mathrm{~d}$ (summer) & \\
\hline & New Zealand & {$[u, T$ measured at $1.2 \mathrm{~m}]$} & 3.9 \\
\hline & & {$[u, T$ reduced to $3.5 \mathrm{~m}]$} & 3.1 \\
\hline Oerlemans (2000) & & {$[u, T$ reduced to $3.5 \mathrm{~m}]$} & $1.2 \pm 0.3$ \\
\hline \multirow[t]{2}{*}{ this study } & Morteratschgletscher, & $1 \mathrm{yr}$ & \\
\hline & Switzerland & {$[u, T$ measured at $3 . \mathrm{b} \mathrm{m}]$} & $1.55 \pm 0.35$ \\
\hline
\end{tabular}

a Values referring to the nominal reference instrument height in this paper $(3.5 \mathrm{~m})$ are in bold. $u=$ windspeed; $T=$ temperature; $C_{S E}=$ bulk exchange coefficient.

The Morteratschgletscher is located in a relatively dry and sheltered valley. This is most obvious from the wind data, showing prevailing katabatic flow of a modest strength. At the AWS site the annual mass balance is strongly negative (loss more than $6 \mathrm{~m}$ w.e.). The amount of snow falling here is only a small fraction of the amount of ice melted. It is not surprising, therefore, that the removal of the winter snowpack proceeds very quickly.

The turbulent fluxes have been determined as a residual in the energy balance. Therefore, the values obtained do not depend on any assumption about the nature of the turbulent exchange. However, if it is assumed that the fluxes can be described by a bulk method, a good agreement between the ice melt calculated from the meteorological data and the measured melt can be obtained with a value of 0.00153 for the turbulent exchange coefficient (reference height $3.5 \mathrm{~m}$ ). In Table 2 this value is compared to values reported in some other energy balance studies. Although many more studies than those listed in the table have been carried out, a value for a bulk exchange coefficient is normally not reported because more complex methods were used to determine the turbulent fluxes (e.g., profile analysis with stability corrections). For the studies listed in Table 2 we made corrections for the differences in sensor height (assuming logarithmic profiles).

We also tried to estimate the error in our value for $C_{s e}$. For a given absolute error in the measurement of ice melt, or in the net radiation, the relative error in $C_{s e}$ is larger when the share of the turbulent heat fluxes in the total energy consumed by the melting process is smaller. In our case this share is about $25 \%$, as can be seen by comparing the ablation curve with a curve obtained with the turbulent heat flux set to zero (Fig. 8). From the spread in the stake measurements we conclude that the error in the total ablation is about $0.3 \mathrm{~m}$. The error in the total net radiation is estimated to be $5 \%$, which corresponds to about 0.25 $\mathrm{m}$ of melted ice. Assuming these errors to be independent, the error in the estimated ablation associated with the turbulent heat fluxes is $0.4 \mathrm{~m}$. This then converts to a $23 \%$ error in the value of $C_{s}$. The values listed in Table 2 agree well except for the study by Hay and Fitzharris (1988) on Ivory Glacier. Here a much larger value is found for unknown reasons. Possible errors introduced by the instrument height correction cannot explain the difference.

The data from AWS on glaciers are very useful to validate mass-balance models that calculate the energy fluxes explicitly. We are currently developing a spatially distributed energy and mass-balance model for the Morteratschgletscher at $25 \mathrm{~m}$ reso- lution. This model is forced by meteorological observations from nearby weather stations. It makes an accurate calculation of the distribution of solar radiation, dealing with the effects of slope, aspect, and shading by surrounding orography. The model contains a large number of parameterizations of the relevant micrometeorological processes. The AWS data are used to optimize these parameterizations. A second AWS has been placed about $600 \mathrm{~m}$ higher on the glacier, but due to technical problems (and bad luck) a complete 1-yr data set has not yet been obtained.

From a more general point of view we expect that the yearround operation of AWS on glaciers will significantly enhance our knowledge of the processes that determine addition and removal of mass from the glacier surface. Studies with data from AWS operated in West Greenland, Vatnajökull (Iceland), and Hardangerjökulen and Storbreen (Norway) are underway. Since these glaciers are located in regions with widely differing climates, we may hope to obtain a broader view of the microclimate of glaciers and how this affects the sensitivity of glacier mass balance to climate change.

\section{Acknowledgments}

We are grateful to the members of the Ice-and-Climate group at the Institute for Marine and Atmospheric Research, Utrecht University, for comments and suggestions.

\section{References Cited}

Ambach, W., 1963: Untersuchungen zum Energieumsatz in der Ablationszone des Grönlandischen Inlandeises. Meddelelser om Gronland, 174(4). 311 pp.

Andreas, E., 1987: A theory for the scalar roughness and the scalar transfer coefficients over snow and sea ice. BoundaryLayer Meteorology, 38: 159-184.

Bintanja, R. and Van den Broeke, M. R., 1995: Momentum and scalar transfer coefficients over aerodynamically smooth Antarctic surfaces. Boundary-Layer Meteorology, 74: 89-111.

Björnsson, H., 1972: Bægisarjökull, North Iceland. Results of glaciological investigations 1967-1968, Part II. The energy balance. Jökull, 22: 44-59.

Denby, B., 2001: Modelling and interpretation of turbulent fluxes in katabatic flows: applications to glaciers and the Greenland ice sheet. Ph.D. thesis, Utrecht University, The Netherlands. $163 \mathrm{pp}$.

Garratt, J., 1992: The Atmospheric Boundary Layer. Cambridge: Cambridge University Press. 316 pp.

Greuell, W. and Oerlemans, J., 1987: Sensitivity studies with a mass balance model including temperature profile calculations 
inside the glacier. Zeitschrift für Gletscherkunde und Glazialgeologie, 22: 101-124.

Greuell, W., Knap, W., and Smeets, P., 1997: Elevational changes in meteorological variables along a midlatitude glacier during summer. Journal of Geophysical Research, 102 (D22): 2594125954.

Hay, J. E. and Fitzharris, B. B., 1988: A comparison of the energy-balance and bulk aerodynamic approaches for estimating glacier melt. Journal of Glaciology, 34(117): 145-153.

Hogg, I. G. G., Paren, J. G., and Timmis, R. J., 1982: Summer heat and ice balances on Hodges Glacier, South Georgia, Falkland Islands Dependencies. Journal of Glaciology, 28(99): 221-238.

Ishikawa, N., Owens, I. F., and Sturman, A. P., 1992: Heat balance characteristics during fine periods on the lower parts of the Franz Josef Glacier, South Westland, New Zealand. International Journal of Climatology, 12: 397-410.

Kondo, J. and Yamazawa, H., 1986: Bulk transfer coefficient over a snow surface. Boundary-Layer Meteorology, 34: 123135.

Kuhn, M., 1978: Die Höhe des Geschwindigkeitsmaximums im Gletscherwind als Parameter des Wärmehaushalts. Arbeiten aus der Zentralanstalt für Meteorologie und Geodynamik, Wien, 31, 69/1-69/8.

Kuhn, M., 1989: The response of the equilibrium line altitude to climate fluctuations: theory and observations. In Oerlemans, J. (ed.), Glacier Fluctuations and Climatic Change. Dordrecht: Kluwer, 407-417.

Munro, D. S., 1989: Surface roughness and bulk heat transfer on a glacier: comparison with eddy correlation. Journal of Glaciology, 35(121): 343-348.

Munro, D. S. and Davies, J. A., 1978: On fitting the log-linear model to wind speed and temperature profiles over a melting glacier. Boundary-Layer Meteorology, 15: 423-437.
Oerlemans, J., 1998: The atmospheric boundary layer over melting glaciers. In Holtslag, A. A. M. and Duynkerke, P. G. Clear and Cloudy Boundary Layers. Amsterdam: Royal Netherlands Academy of Arts and Sciences, VNE 48, 129-153.

Oerlemans, J., 2000: Analyis of a three-year meteorological record from the ablation zone of the Morteratschgletscher, Switzerland: energy and mass balance. Journal of Glaciology, 46(155): 571-579.

Oerlemans, J., 2001: Glaciers and Climate Change. Lisse: Balkema. 148 pp.

Oerlemans, J. and Knap, W. H., 1998: A one-year record of global radiation and albedo from the ablation zone of the Morteratschgletscher, Switzerland. Journal of Glaciology, 44(147): 231-238.

Oerlemans, J., Björnsson, H., Kuhn, M., Obleitner, F, Palsson, F., Smeets, P., Vugts, H. F., and De Wolde, J., 1999: A glaciometeorological experiment on Vatnajökull, Iceland. BoundaryLayer Meteorology, 92: 3-26.

Ohata, T., Zhongyuan, B., and Limgfu, D., 1989: Heat balance study on Glacier No. 1 at head of Urumqi River, Tianshan Mountains, China. Journal of Glaciology and Geocryology, 11: 298-310.

Smeets, C., Duynkere, P. G., and Vugts, H. F., 1999: Observed wind profiles and turbulent fluxes over an ice surface with changing surface roughness. Boundary-Layer Meteorology, 92: 101-123.

Van den Broeke, M. R., Duynkerke, P. G., and Henneken, E. A. C., 1994: Heat, momentum and moisture budgets of the katabatic layer over the melting zone of the west Greenland ice sheet in summer. Boundary-Layer Meteorology, 71: 393-413.

Ms submitted December 2001

\section{ERRATUM}

Lindsey J. McEwen, John A. Matthews, Richard A. Shakesby, and Mark S. Berrisford, "Holocene Gorge Excavation Linked to Boulder Fan Formation and Frost Weathering in a Norwegian Alpine Periglaciofluvial System," Arctic, Antarctic, and Alpine Research, Vol. 34, No. 3, 2002, p. 355.
The List of Symbols should be replaced with the following corrected list.

\section{List of Symbols}

$V_{\mathrm{g}} \quad$ gorge volume $\left(\mathrm{m}^{3}\right)$

$V_{\mathrm{sg}} \quad$ component of gorge volume attributed to subglacial (pre-Holocene) erosion $\left(\mathrm{m}^{3}\right)$

$V_{\mathrm{h}} \quad$ component of gorge volume attributed to Holocene erosion $\left(\mathrm{m}^{3}\right)$

$V_{\mathrm{f}} \quad$ boulder fan volume $\left(\mathrm{m}^{3}\right)$

$V_{1} \quad$ angular small caliber load lost from the boulder fan $\left(\mathrm{m}^{3}\right)$

$V_{\mathrm{fw}} \quad$ gorge volume lost through frost weathering $\left(\mathrm{m}^{3}\right)$

$V_{\text {ca }} \quad$ gorge volume lost through corrosion or abrasion $\left(\mathrm{m}^{3}\right)$

$V_{\text {co }} \quad$ gorge volume lost through corrosion or chemical weathering $\left(\mathrm{m}^{3}\right)$

$S_{\text {crit(p) }}$ the proportion of gorge source sediments below a critical size 